\title{
EDITORIAL
}

\section{THE MAGIC OF SPELLS}

\author{
J.E. MORLEY
}

Corresponding author: John E. Morley, MB, BCh, Division of Geriatric Medicine, Saint Louis University School of Medicine, 1402 S. Grand Blvd., M238, St. Louis, MO 63104, Email: john.morley@health.slu.edu

\section{"Those who suffer from frequent and strong faints, without any manifest cause die suddenly" \\ rippocrates (460-373 BC)}

A spell is a brief period where a person is dissociated from the world around them or loses consciousness. There are many possible causes of spells (Table 1) (1). The two major causes of spells are seizures and syncope. Often making the diagnosis is elusive (2). The approach to the differential diagnosis is given in Table 2.

\section{Table 1}

Causes of Spells

\begin{tabular}{ll}
\hline Syncope & \\
Seizures & \\
Dizziness & \\
Anxiety & \\
Pulmonary embolus & \\
Cerebral vascular accident & \\
Drop attack & \\
Migraine & \\
Narcolepsy & -hypoglycemia \\
Metabolic & -hypoxemia \\
& -hypocalemic tetany \\
& -Alkalotic tetany \\
& -Acidosis \\
& -hypercapnia \\
& -low carbon dioxide (hyperventilation) \\
\hline
\end{tabular}

\section{Seizures}

The incidence of seizures increases exponentially after 60 years of age (3). In older persons it can take up to 17 years to make the diagnosis. Seizures may be either generalized (toniclonic, absence, myoclonic or atonic) or partial, where they are unilateral and consciousness can be preserved. Complex partial and generalized tonic clonic seizures make up over half of seizures (4). Fyodor Dostyeski (1821-1880) was the prototypic example of complex partial seizures where he Received December 19, 2019 presented with ecstasy or anguish followed by convulsions. Complex partial seizures can present with hallucinations (visual, auditory or olfactory), psychomotor (dysphagia, chewing, taking off clothes) or temporal (dreamy state, memory problems, fear or déjà vu). Diagnostic clues include elevated prolactin for a 20 to 60 -minute window following the seizure and, in some cases, elevated CPK or lactate $(5,6)$. The diagnosis of seizures is made by electroencephalogram. Artificial intelligent techniques are being developed to enhance the diagnosis (7).

\section{Syncope}

There are multiple common causes of syncope (Table 3) and a number of much less common causes of syncope (the black swans or zebras) (Table 4) (8). The mechanisms of syncope are:

- Cardiogenic syncope - heart fails as a pump

- Orthostatic syncope - reduced venous return

- Abnormal arterial vasodilation - inappropriate arterial vasodilation

- Atherosclerosis

Cardiac syncope can be due to tachycardia, bradycardia, asystole, prolonged QT, hypertrophic obstructive cardiac myopathy, amyloid cardiac infiltration, or Brugada syndrome. Brugada syndrome is right bundle branch block with ST segment elevation in V1 to V3 (9). It occurs predominantly in middle aged persons. Persons with this syndrome have a propensity to develop sustained ventricular arrythmias. Carotid sinus hypersensitivity occurs in $40 \%$ of adults over 65 years (10). It results in abnormal cerebral autoregulation. It is a common cause of falls in older individuals. Diagnosis is made by doing carotid sinus massage. If there is a pause of greater than 7 seconds in older persons, this is diagnostic. It should be avoided in persons with a carotid brunt, recent stroke or myocardial infarction or a history of ventricular tachycardia (11). The work up for cardiac syncope is outlined in Figure 1. Persons with autonomic neuropathy are at high risk of having lethal arrythmias ("death in the bed syndrome") (11). If no obvious cardiac causes, orthostasis or postprandial hypotension are present, an elderly person with syncope should be considered for a subcutaneous implantable loop recorder (12). Ambulatory recorders rarely are useful as usually the next syncopal episode occurs months after the previous one.

Published online January 16, 2020, http://dx.doi.org/10.1007/s12603-020-1322-7 
THE JOURNAL OF NUTRITION, HEALTH \& AGING

Table 2

Differential Diagnosis of Seizures and Syncope

\begin{tabular}{lll}
\hline & Seizure & Syncope \\
\hline Onset & Sudden & $\begin{array}{l}\text { Prodrome (nausea, palpitations, dizziness, visual } \\
\text { disturbances, flushing) }\end{array}$ \\
Muscle activity & Tonic/clonic activity & Floppy \\
& Automatism & Slump \\
Incontinence & Unusual posturing & \\
Injury & Common & Rare \\
& Tongue biting & Rare \\
& Lacerations & \\
Acidosis & Dislocations & \\
Recovery & Bruises & None \\
& Metabolic acidosis & Event may or may not be recalled \\
& Event not recalled & \\
\hline
\end{tabular}

Table 3

Common Causes of Syncope

\begin{tabular}{|c|c|}
\hline \multicolumn{2}{|l|}{ Vasovagal } \\
\hline \multirow[t]{9}{*}{ Cardiogenic syncope } & Tachycardia \\
\hline & Bradycardia \\
\hline & Asystole \\
\hline & Prolonged QT \\
\hline & Myxoma \\
\hline & $\begin{array}{l}\text { Hypertrophic obstructive cardiac } \\
\text { myopathy }\end{array}$ \\
\hline & Brugada Syndrome \\
\hline & Amyloid myopathy \\
\hline & Carotid sinus hypersensitivity \\
\hline \multicolumn{2}{|l|}{ Dehydration } \\
\hline \multicolumn{2}{|l|}{ Anemia } \\
\hline \multicolumn{2}{|l|}{ Vasodilation } \\
\hline \multicolumn{2}{|c|}{ Autonomic dysfunction } \\
\hline \multicolumn{2}{|l|}{ Postural hypotension } \\
\hline \multicolumn{2}{|c|}{ Postprandial hypotension } \\
\hline \multicolumn{2}{|l|}{ Drug induced } \\
\hline \multirow[t]{5}{*}{ Valsalva maneuver } & Weight lifting \\
\hline & Trumpet blowing \\
\hline & Tussive syncope \\
\hline & Mictutition syncope \\
\hline & Deglutition syncope \\
\hline
\end{tabular}

Orthostatic syncope occurs when there is greater than $20 \%$ of the blood volume pooling in the extremities on standing.
It is often associated with excessive loss of water or blood, failed vasoconstriction (varicose veins), sarcopenia (lack of muscle contraction) increased chest or abdominal pressure (e.g., abdominal corset), drugs, neuropathy or vasodilation due to spending time in a jacuzzi (13). Orthostasis is not always associated with dizziness so standing blood pressure needs to be measured in all older persons and in all persons with diabetes mellitus. Table 5 lists the treatment approaches for orthostatic hypotension (14).

Table 4

Rare Causes of Syncope (Black Swans and Zebras)

Pheochromocytoma

Systemic mastocytosis

Addison's disease

VIPoma (Verner-Morrison Syndrome)

Vagal paraganglionomas

Giant cell arteritis

Paraplegic induced cerebral syncope

Eagle syndrome (elongated styloid process)

Acupuncture induced syncope ("Yun-Cheng" phenomenon)

\section{Postprandial Hypotension ("Big Mac Attack")}

Thirty to 120 minutes following a meal blood pressure can drop fairly dramatically. This postprandial hypotension is variable and occurs more often in the morning (15). It occurs in about a quarter of older persons and results in falls, syncope, stroke, myocardial infarction and death. The fall in blood pressure is mainly due to carbohydrates in meals. The fall in 


\section{THE MAGIC OF SPELLS}

blood pressure is due to the vasodilatory of calcitonin gene related peptide (16). Postprandial hypotension can be treated with coffee in the morning only, small meals, fiber with the meals and alpha-1 glucosidase inhibitors, e.g., acarbose and miglitol, which slow gastric emptying by increasing glucagonlike peptide 1 .

Table 5

Management of Orthostasis

\section{Eliminate medication}

Add salt

Elevate head of bed

Bedside commode

Get up slowly

Exercise training for orthostasis

Leg crossing

Coffee in morning

Drugs

-Midodrin (alpha-1 adrenegic antagonist)
-Nonsteroid anti-inflammatory drugs 'e.g., Motrin
-Fludrocortisone
-Erythropoetin
-Desmopressin
-3,4 di-threo-diphenoxyphenyl serine
-Droxidropa - prodrug to norepinephrine

Figure 1

Diagnosis of Syncope

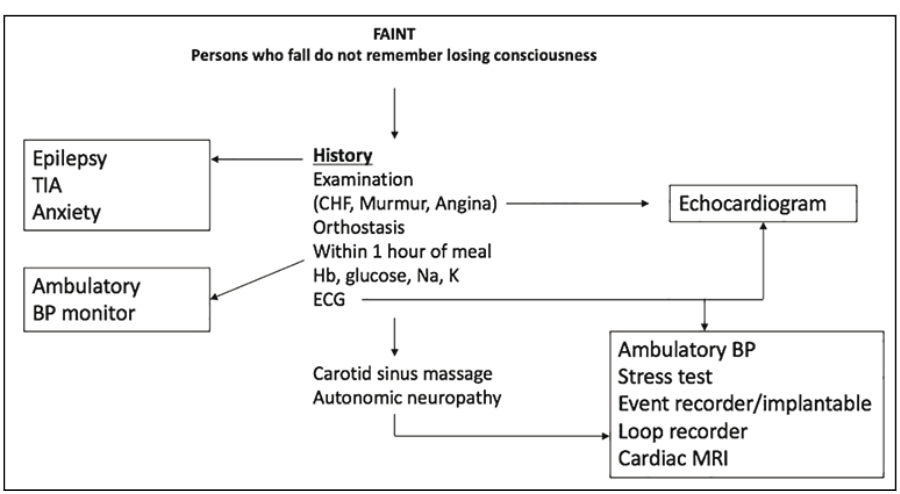

\section{Dizziness (Vertigo)}

With vertigo "the external world seems to revolve around the individual or the individual seems to revolve in space." Like syncope there are multiple causes of dizziness (19). These include benign paroxysmal positional vertigo (BPPV), Meniere's disease, labyrinthitis, vestibular neuronitis, acoustic neuroma, arteriosclerosis, ototoxicity and osteoarthritis.

BPPV occurs in the fifth to seventh decades of life and is responsible for $20 \%$ of all cases (20). It is bilateral in $10 \%$. It can be treated with the Epley maneuver.

Meniere's disease occurs when endolymph cannot be drained from the inner ear (21). It presents with episodes of dizziness and tinnitus. There is fluctuation in sensorineural hearing and a feeling of pressure in the ear. Table 6 lists possible treatments for Meniere's disease.

Superior semicircular canal dehiscence occurs in $0.4 \%$ to $1.5 \%$ (22). It presents with disequilibrium that can be triggered by noise, gaze or pressure and can be associated with nystagmus. Treatment consists of a pressure equalization tube or surgical repair (23).

Finally, a number of exercises have been developed to treat dizziness (24). These include Brandt-Baroff Habituation exercise, the Sermont (Liberatory) Maneuver, Gaze Stabilization exercises and Crawthorne-Cooksey exercises. These exercises are variably effective.

\section{Conclusion}

Spells are very common in older persons. They result in falls, frailty, disability and death. The diagnosis is often difficult to make. With the exception of postprandial hypotension, treatment success is variable.

Disclosures: The authors declare there are no conflicts.

\section{References}

1. Mechanic OJ, Grossman SA. Syncope and related paroxysmal spells. StatPearls Publishing LLC; 2019, Apr 3 PMID: 29083598 [Epub]

2. McKeon A, Vaughan C, Delanty N. Seizure versus syncope. Lancet Neurol 2006;5:171-180.

3. Hauser WA, Annegers JF, Kurland LT. Incidence of epilepsy and unprovoked seizures I Rochester, Minnesota: 1935-1984.

4. Lezaic N, Roussy J, Masson H, et al. Epilepsy in the elderly: Unique challenges in an increasingly prevalent population. Epilepsy Behav 2019;102:106724. [Epub ahead of print].

5. Nass RD, Sassen R, Elger CE, Surges R. The role of postictal laboratory blood analyses in the diagnosis and prognosis of seizures. Seizure 2017;47:51-65.

6. Javali M, Acharya $\mathrm{P}$, Shah $\mathrm{S}$, et al. Role of biomarkers in differentiating new-onset seizures from psychogenic nonepileptic seizures. J Neurosci Rural Pract 2017;8:581584.

7. Daoud H, Bayoumi MA. Efficient epileptic seizure prediction based on deep learning. IEEE Trans Biomed Circuits Syst 2019;13:804-813.

8. Palaniswamy C, Aronow WS, Agrawal N, et al. Syncope: Approaches to diagnosis and management. Am J Ther 2016;23:e208-e217.

9. Brugada P, Brugada J. Right bundle branch block, persistent ST segment elevation and sudden cardiac death: A distinct clinical and electrocardiographic syndrome. A multicenter report. J Am Coll Cardiol 1992;20:1391-1396.

10. Cronin H, Kenny RA. Cardiac causes of falls and their treatment. Clin Geriatr Med 2010;26:539-567.

11. Bissinger A. Cardiac autonomic neuropathy: Why should cardiologists care about that? J Diabetes Res 2017;2017:53741767. Doi: 10.1155/2017/5374176. [Epub 2017 ahead of print]

12. Bisignani A, De Bonis S, Mancuso L, et al. Implantable loop recorder in clinical practice. J Arrhythm 2018;35:25-32.

13. Freeman R, Abuzinadah AR, Gibbons C, et al. Orthostatic hypotension: JACC stateof-the-art review. J Am Coll Cardiol 2018;72:1294-1309.

14. Joseph A, Wanono R, FLamant M, Vidal-Petiot E. Orthostatic hypotension: A review. Nephrol Ther 2017;13(Suppl 1):S55-S67. Doi: 10.1016/j.nephro.2017.01.003.

15. Morley JE. Editorial: Postprandial hypotension - the ultimate Big Mac Attach. J Gerontol A Biol Sci Med Sci 2001;56:M741-M743.

16. Edwards BJ, Perry HM 3rd, Kaiser FE, et al. Relationship of age and calcitonin generelated peptide to postprandial hypotension. Mech Ageing Dev 1996;87:61-73.

17. Trahair LG, Horowitz M, Jones KL. Postprandial hypotension: A systematic review. J Am Med Dir Assoc 2014;15:394-409.

18. Shams A, Morley JE. Editorial: Autonomic neuropathy and cardiovascular disease in 


\section{THE JOURNAL OF NUTRITION, HEALTH \& AGING}

aging. J Nutr Health Aging 2018;22:1028-1033.

19. Zwergal A, Dieterich M. Vertigo and dizziness in the emergency room. Curr Opin Neurol 2019;Nov 16, doi: 10.1097/WCO.0000000000000769. [Epub ahead of print]

20. Balatsouras DG, Koukoutsis G, Fassolis A, et al. Benign paroxysmal positional vertigo in the elderly: Current insights. Clin Interv Aging 2018;13:2251-2266.

21. Harcourt J, Barraclough K, Bronstein AM. Meniere's disease. MBJ 2014;349:g6544 Doi: $10.1136 / \mathrm{bmj} . \mathrm{g} 6544$.

22. Mau C, Kamal N, Badeti S, et al. Superior semicircular canal dehiscence: Diagnosis and management. J Clin Neurosci 2018:48:58-65.
23. Gioacchini FM, Alicandri-Ciufelli M, Kaleci S, et al. Outcomes and complications in superior semicircular canal dehiscence surgery: A systematic review. Laryngoscope 2016;126:1218-1224

24. Kendall JC, Hartvigsen J, Azari MF, French SD. Effects of nonpharmacological interventions for dizziness in older people: Systematic review. Phys Ther 2016;96:641-649. 